\title{
Sleep disturbances among patients with epilepsy
}

This article was published in the following Dove Press journal:

Neuropsychiatric Disease and Treatment

10 July 2017

Number of times this article has been viewed

\author{
Anna Staniszewska' \\ Agnieszka Mąka' \\ Urszula Religioni \\ Dominik Olejniczak ${ }^{3}$ \\ 'Department of Experimental and \\ Clinical Pharmacology, Medical \\ University of Warsaw, Warsaw, Poland, \\ ${ }^{2}$ Collegium of Socio-Economics, \\ Warsaw School of Economics, \\ Warsaw, Poland, ${ }^{3}$ Department of \\ Public Health, Medical University of \\ Warsaw, Warsaw, Poland
}

Aim: The aim of this study was to analyze the prevalence of sleep disorders among patients with epilepsy and to compare the incidence of sleep disorders between the clinical and demographics factors.

Materials and methods: The study was conducted among 302 patients with epilepsy. Sleep disturbances were measured with the Polish version of the Pittsburgh Sleep Quality Questionnaire (PSQI). The questionnaire prepared and applied by the authors contained questions relating to sociodemographic characteristics, clinical status, and sleep.

Results and conclusion: Mean PSQI score in the study group was $9 \pm 2$ points, with the range of 4-16 points. PSQI test results were analyzed with regard to clinical and demographic characteristics of those suffering from epilepsy: gender, age, profession, body mass index, illness duration, number of medicines taken, type of seizures, frequency of seizures, time which elapsed since last seizure, provocative factor of seizure attacks, occurrence of adverse effects of antiepileptic drugs (AEDs). Furthermore, the existence of a relationship between PSQI test result and particular sleep-related factors or particular sleep conditions was examined. However, the examination of a relationship between certain independent variables and the final PSQI test result did not prove the existence of a statistically relevant influence (in all cases $P>0.05$ ).

Keywords: epilepsy, sleep disturbances, sleep, PSQI

\section{Introduction}

Sleep disorders pose a serious health problem in the contemporary world. ${ }^{1}$ In Poland, approximately $23.7 \%$ of the population suffer from sleep disorders. ${ }^{2}$ A study conducted in a group of 1,000 Polish citizens showed that 39\% of all sleep disorders are caused by insomnia. ${ }^{3}$ Among important factors influencing sleep, there are several diseases, such as epilepsy and taking numerous chemicals. Literature have shown that epileptic population had significantly lower efficiency of sleep, had more N2 nonrapid eye movement (NREM) sleep, and had less rapid eye movement (REM) sleep with prolonged latency to REM sleep in comparison to general population. ${ }^{4-7}$ The relationship between epilepsy and sleep dysfunction/disorders is complex. On the one hand, seizures may be exacerbated by sleep deprivation and on the other hand, some seizures occur mainly during sleep. Furthermore, while sleep disorders may negatively impact epilepsy, epilepsy may aggravate certain sleep disorders. ${ }^{4}$ Antiepileptic drugs (AEDs) may interfere with a normal sleep pattern and excessive daytime sleepiness. The correlation between AEDs and sleep dysfunction/disorders is unclear. Some authors have shown a strong influence effect of AEDs on daytime virility and sleep, ${ }^{8,9}$ but other researchers did not report any effect of antiepileptic medication on sleep. ${ }^{10}$ However, sudden withdrawal of antiepileptic drugs is a risk factor for the occurrence of status epileptic seizures in previously pure sleep epilepsy. ${ }^{11}$ Sleep is a potent activator of seizures. 


\section{Objective}

The aim of this study was to analyze the prevalence of sleep disorders in patients with epilepsy and to compare the incidence of sleep disorders with regard to clinical and demographic factors.

\section{Materials and methods Study design and participants}

The study was conducted among patients with epilepsy in the period from October 2015 to October 2016. Participants were recruited through multiple channels, including online websites, a forum for people suffering from epilepsy, and a neurological outpatient clinic in Warsaw. The inclusion criteria were the age of $\geq 18$ years, patient's epilepsy, and consent to participate in the study. Exclusion criteria included mental retardation, psychiatric comorbidities, and night or shift work.

Initially, 356 patients agreed to participate in the study. The final analysis covered surveys completed by 302 patients (response rate $84.8 \%$ ). The remaining 54 surveys were rejected due to missing information.

\section{Clinical assessment and sleep questionnaires}

Sleep disturbances were measured with the Polish version of the Pittsburgh Sleep Quality Questionnaire (PSQI). The PSQI has internal consistency and a reliability coefficient (Cronbach's alpha) of 0.83 for its 7 components. The PSQI is a 19-item self-rated questionnaire used for evaluating subjective sleep quality during the previous month. The PSQI is a questionnaire designed to evaluate the following: overall sleep quality, sleep quality, sleep latency, sleep duration, sleep efficiency, sleep disturbance, medication use, and daytime dysfunction. ${ }^{12}$ Each answer was scored on a scale of $0-3$ ( $0=$ no difficulty, $3=$ severe difficulty). Component scores were added to obtain a global score of $0-21$. Higher scores indicated worse sleep quality. A global sum of $\geq 5$ was considered poor overall sleep quality and $\geq 10$ was severely disturbed sleep.

The questionnaire prepared and applied by the authors contained questions relating to sociodemographic characteristics, clinical status, and sleep.

Demographic characteristics consisted of 5 items: gender, age, educational level, height, and weight. Clinical status consisted of 10 items: duration of disease, kind of seizures, frequency of seizures, last seizure, mode of therapy, type of AEDs, side effects of AEDs associated with sleep, provocative factors of seizure attacks, sleep disorders and kind of sleep disorders. In the third part, the respondents provided answers to questions concerning factors affecting sleep (7 questions) and conditions conducive to sleeping (5 questions). Tables $1-5$ show all possible answers. The respondents were advised about the purpose of the study. Participation was voluntary and anonymous. Completion of the survey meant that the patients gave their consent to participate in the study.

\section{Ethics}

The study was approved by the Ethics Committee, Medical University of Warsaw (No AKBE/159/16).

\section{Statistical analysis of the obtained results}

The single factor analysis of variance (ANOVA) and KruskalWallis test were used for the purpose of statistical analysis of results variance between the study groups. The nonparametric Mann-Whitney $U$-test and Student's $t$-test were used for the comparison of differences between the 2 study groups. The level of significance $(P<0.05)$ was accepted as statistically reliable. The statistical analysis of obtained results was performed using STATISTICA (10.0) software.

\section{Results}

\section{Demographic data of the respondents}

There were 302 patients: 116 males and 186 females. The mean age in years was $34.2 \pm 13.3$ with the range $18-75$ years. Mean body height and weight were $171.6 \pm 9.5 \mathrm{~cm}$ and $71.9 \pm 17.1 \mathrm{~kg}$, respectively. The mean body mass index (BMI) was $24.9 \pm 5.2 \mathrm{~kg} / \mathrm{m}^{2}$, range $17.1-38.1 \mathrm{~kg} / \mathrm{m}^{2}$, with 26 patients being underweight, 50 obese, and 66 overweight.

Table I Sociodemographics characteristics of the respondents

\begin{tabular}{ll}
\hline Variable & $\mathbf{N}(\%)$ \\
\hline Gender & $116(38.4)$ \\
Male & $186(61.6)$ \\
Female & \\
Age (years) & $34.2 \pm 13.3,18-75$ \\
$\quad$ Mean \pm SD, range & \\
Height $(\mathrm{cm})$ & $171.6 \pm 9.5,150-198$ \\
Mean \pm SD, range & \\
Weight $(\mathrm{kg})$ & $71.9 \pm 17.1,43-140$ \\
Mean \pm SD, range & \\
BMI (kg/m²) & $24.9 \pm 5.2,17.1-38.1$ \\
Mean \pm SD, range & \\
Employment status & $48(16.0)$ \\
Unemployed & $120(39.7)$ \\
Employed & $68(22.5)$ \\
Student & $46(15.2)$ \\
Pension & $20(6.6)$ \\
Own business &
\end{tabular}

Abbreviation: BMI, body mass index. 
Table 2 Clinical characteristics of the respondents

\begin{tabular}{|c|c|}
\hline Variables & $\mathbf{N}(\%)$ \\
\hline Duration of epilepsy, months (mean \pm SD) & $197.9 \pm 160.6$ \\
\hline Range & $2-708$ \\
\hline \multicolumn{2}{|l|}{ Seizure frequency } \\
\hline$<$ I/year & $116(8.4)$ \\
\hline$<\mathrm{I} /$ month & $36(11.9)$ \\
\hline I-3/month & $62(20.5)$ \\
\hline$>$ I/week & $88(19.1)$ \\
\hline \multicolumn{2}{|l|}{ Type of seizure } \\
\hline Partial & $90(29.8)$ \\
\hline Primarily generalized & $84(27.8)$ \\
\hline Secondarily generalized & $92(30.5)$ \\
\hline Secondarily generalized + partial & $36(11.9)$ \\
\hline \multicolumn{2}{|l|}{ How long is a patient seizure-free } \\
\hline$>$ I/year & $90(29.8)$ \\
\hline$<\mathrm{I} /$ month & $34(11.3)$ \\
\hline $\mathrm{I}-3 /$ month & $42(13.9)$ \\
\hline$>$ I/week & $136(45.0)$ \\
\hline \multicolumn{2}{|c|}{ Most common provocative factors of seizure attacks } \\
\hline Lack of sleep & $82(27.2)$ \\
\hline Alcohol or other stimulant & $48(15.9)$ \\
\hline Stress & $110(36.4)$ \\
\hline Change the AEDs & $24(7.9)$ \\
\hline There is no reason & $22(7.3)$ \\
\hline Other & $16(5.3)$ \\
\hline \multicolumn{2}{|l|}{ Mode of therapy } \\
\hline Free of medication & $10(3.3)$ \\
\hline Monotherapy & $160(53.0)$ \\
\hline Polytherapy & $132(43.7)$ \\
\hline \multicolumn{2}{|l|}{ Type of AEDs* } \\
\hline CBZ & $98(32.5)$ \\
\hline BZD & $10(3.3)$ \\
\hline ETX & $2(0.7)$ \\
\hline GBP & $22(7.3)$ \\
\hline LSM & $4(1.3)$ \\
\hline LTG & $48(15.9)$ \\
\hline LEV & $62(20.6)$ \\
\hline OXC & $32(10.6)$ \\
\hline VPA & $136(45)$ \\
\hline TGB & $12(4)$ \\
\hline TPM & $28(9.3)$ \\
\hline VGB & $8(2.6)$ \\
\hline \multicolumn{2}{|l|}{ Side effects of AEDs associated with sleep } \\
\hline Yes & $120(39.7)$ \\
\hline No & $182(60.3)$ \\
\hline \multicolumn{2}{|l|}{ Sleep disorders } \\
\hline Yes & $176(58.3)$ \\
\hline No & $126(4 \mid .7)$ \\
\hline \multicolumn{2}{|l|}{ Kind of sleep disorders } \\
\hline Insomnia & $54(17.9)$ \\
\hline Hypersomnia & $34(1 \mathrm{I} .3)$ \\
\hline Sleep apnea & $44(14.6)$ \\
\hline RLS & $44(14.6)$ \\
\hline
\end{tabular}

Note: *The data did not give a total of $100 \%$ because the respondents could choose multiple answers.

Abbreviations: AEDs, antiepileptic drugs; BZD, benzodiazepine; CBZ, carbamazepine; ETX, ethosuximide; GBP, gabapentin; LEV, levetiracetam; LSM, lacosamide; LTG, lamotrigine; OXC, oxcarbazepine; RLS, restless legs syndrome; TGB, tiagabine; TPM, topiramate; VGB, vigabatrin; VPA, sodium valproate.
Table 3 PSQI scores of the study group

\begin{tabular}{ll}
\hline PSQI & Mean \\
\hline Sleep quality (CI) & $1.80 \pm 1.00$ \\
Sleep latency (C2) & $1.00 \pm 1.00$ \\
Sleep duration (C3) & $0.95 \pm 0.88$ \\
Sleep efficiency (C4) & $1.09 \pm 1.19$ \\
Sleep disturbance (C5) & $1.85 \pm 0.35$ \\
Medication use (C6) & $0.68 \pm 0.95$ \\
Daytime dysfunction (C7) & $1.22 \pm 0.76$ \\
Total score & $9.00 \pm 2.00$ \\
\hline
\end{tabular}

Abbreviation: PSQI, Pittsburgh Sleep Quality Questionnaire.

The majority of the study population were employed (39.7\%).

Table 1 shows the sociodemographic profile of the study participants.

\section{Clinical data of the respondents}

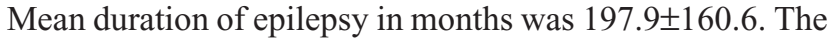
majority of patients had secondarily generalized seizures (30.5\%), followed by complex partial seizures $(29.8 \%)$. Thirty-one patients $(20.5 \%)$ had $1-3$ seizures per month, $19.1 \%>1$ seizures per week, and $11.9 \%<1$ seizures per month. Forty-five (29.8\%) of all patients had been seizurefree for more than 1 year and the majority of patients had their last seizure more than 1 week before.

Stress $(36.4 \%)$ was the most common provocative factor associated with seizure attacks, followed by sleep deprivation (27.2\%). Twelve patients (7.3\%) had no apparent triggers.

Medication analysis revealed that $53 \%$ of the participants were on monotherapy, whereas $43.7 \%$ were on polytherapy and 3.3\% were medication-free. The majority of patients were taking valproate $(45 \%)$. Carbamazepine $(32.5 \%)$ was the second most common drug. Side effects of AEDs associated with sleep were reported in $39.7 \%$ patients.

In their responses to clinical questions, $41.7 \%$ of the participants did not indicate any sleep-related problems, $17.9 \%$ had insomnia, an equal number of respondents had restless leg syndrome and sleep apnea (14.6\% each), and only $11.3 \%$ had hypersomnia. Table 2 shows the clinical profile of the study participants.

Table 4 Factors affecting sleep among the study group

\begin{tabular}{llll}
\hline No & Questions & Yes, $\mathbf{n}(\%)$ & No, n (\%) \\
\hline 1 & Problems at work & $184(60.9)$ & $118(19.1)$ \\
2 & Financial problems & $96(31.8)$ & $206(68.2)$ \\
3 & Family/emotional or & $90(29.8)$ & $212(70.2)$ \\
& relationship problems & & \\
4 & The loss of a loved person & $122(40.4)$ & $180(59.6)$ \\
5 & Sadness and low self-esteem & $210(69.5)$ & $92(30.5)$ \\
6 & Epilepsy/seizure & $210(69.5)$ & $92(30.5)$ \\
7 & Social gatherings & $86(18.5)$ & $216(71.5)$ \\
\hline
\end{tabular}


Table 5 Conditions conducive to sleeping in the study group

\begin{tabular}{llll}
\hline No & Questions & Yes, n (\%) & No, n (\%) \\
\hline I & Do you have your own bedroom? & $162(63.6)$ & $140(46.4)$ \\
2 & $\begin{array}{l}\text { Is your bedroom located in a quiet place? } \\
\text { I } 174(57.6)\end{array}$ & $128(42.4)$ \\
3 & $\begin{array}{l}\text { Is there an appropriate temperature in } \\
\text { your bedroom? }\end{array}$ & $254(84.1)$ & $48(15.9)$ \\
4 & $\begin{array}{l}\text { Do you have a comfortable bed and } \\
\text { bedding? }\end{array}$ & $160(53.0)$ & $142(47.0)$ \\
5 & $\begin{array}{l}\text { Do you fall asleep in front of the } \\
\text { television, computer, or reading a book? }\end{array}$ & $134(44.4)$ & $168(55.6)$ \\
\hline
\end{tabular}

\section{Sleep disorders in PSQI}

Mean PSQI score in the study group was $9 \pm 2$ points, with the range of 4-16 points. The worst rating concerned the domain of sleep disturbances with a mean of 1.85. Six of the 302 patients had undisturbed sleep, whereas 296 of them had disturbed sleep, including 92 suffering from severely disturbed sleep. Detailed scores obtained are presented in Table 3.

In the study group, epilepsy/seizure, sadness, and low self-esteem were factors affecting sleep (Table 4) for an equal number of respondents $(69.5 \%$ each). The majority of the respondents had their own bedroom (63.6\%), comfortable bed $(53.0 \%)$, and situated in a quiet place $(57.6 \%)$, where the temperature was adjusted to sound sleep (84.1\%) (Table 5).

\section{Statistical analysis}

PSQI test results were analyzed with regard to clinical and demographic characteristics of those suffering from epilepsy: gender, age, profession, BMI, illness duration, number of medicines taken, type of seizures, frequency of seizures, time which elapsed since last seizure, provocative factor of seizure attacks, and occurrence of adverse effects of AEDs. Furthermore, the existence of a relationship between PSQI test result and particular sleep-related factors or particular sleep conditions was examined. However, the examination of a relationship between certain independent variables and the final PSQI test result did not prove the existence of a statistically relevant influence (in all cases $P>0.05$ ).

\section{Discussion}

The main aim of this study was to analyze the prevalence of sleep disorders in patients with epilepsy and to compare the incidence of sleep disorders with regard to clinical and demographic factors.

The prevalence of excessive daytime sleepiness in patients suffering from epilepsy is as high as $16.9 \%-28 \%,{ }^{12,13}$ whereas that of insomnia is $24.6 \%-34 \%{ }^{14,15}$ Our study proves that in those suffering from epilepsy, insomnia is more frequent
(17.9\%) than hypersomnia (11.3\%). In India, $24.6 \%$ of patients with epilepsy had sleep disorders. ${ }^{16}$

Another sleep disorder is restless legs syndrome (RLS) syndrome which occurs frequently in patients taking antiepileptic drugs ${ }^{17}$ and those suffering from obstructive sleep apnea. RLS syndrome prevalence in patients with epilepsy amounts to $10.2 \%-28.2 \% .{ }^{14}$ In our study, $14.6 \%$ of patients revealed that they suffer from the RLS and $14.6 \%$ suffer from an obstructive sleep apnea. Coincidence of epilepsy and sleep apnea syndrome may cause excessive daytime sleepiness or induce epileptic seizures. ${ }^{18}$

Our initial hypothesis was that the sociodemographic and clinical variables impact sleep quality. The impact of sociodemographic (age, gender, and employment status) and clinical variables (duration of epilepsy, seizure type and frequency, and type and kind of treatment) on sleep disorders was analyzed. This study did not demonstrate any correlation between sleep quality and demographic or clinical factors, or selected factors affecting sleep and conditions conducive to sleeping (in all cases, $P>0.005$ ). Hypothesis is rejected.

Similarly, in the studies by Moser et al,${ }^{14}$ Alvarez Guerrico et al, ${ }^{19}$ and Carrion et al, ${ }^{20}$ significant differences in PSQI according to age, gender, and type of epilepsy were not found. Sleep disorders are one of the most common factors leading to health problems. The results obtained in the current study revealed that poor sleep quality was common in patients with epilepsy, the mean score of PSQI was $9 \pm 2$.

Table 6 summarizes the results among patients diagnosed with epilepsy on PSQI scale within the studies conducted in different countries. It can be observed that the only country where the result obtained by the patients ( 4.88 points) demonstrated good quality of sleep of those suffering from epilepsy was Austria. ${ }^{14}$ A study conducted in Slovakia resulted in an 18.52 point score, which demonstrates a very bad quality of sleep. ${ }^{25}$

The data presented in Table 6 differ substantially depending on the country and the area of the world. This results from observation period, population and age of epileptic patient, seizure, and therapy. Nonetheless, it should be stressed that the groups which were compared differed in size and that the population chosen for this study by the author was the biggest $(\mathrm{N}=302)$.

It turned out that the biggest problem for the patients surveyed was sleep quality, which is in concordance with the results of other studies by Turaga et $\mathrm{al}^{16}$ and Chen et $\mathrm{a}^{27}$ ( 1.8 vs 0.75 vs 1.2 , respectively in PSQI scale). Results of subscales of sleep disturbance are the biggest problem in our own study and in the study by Chen et $\mathrm{al}^{27}$ (1.85 vs 1.2 ). 
Table 6 PSQI scores of the study group and the other studies

\begin{tabular}{|c|c|c|c|c|}
\hline Author, year & Study design & Place & Population & $\begin{array}{l}\text { Results in } \\
\text { PSQI (total) }\end{array}$ \\
\hline Moser et al, ${ }^{14} 2015$ & $\begin{array}{l}\text { A combined retrospective } \\
\text { and prospective study }\end{array}$ & Austria & 32 patients & $4.88 \pm 2.92$ \\
\hline Wigg et al, ${ }^{21} 2014$ & Cross-sectional & Brasil & I3 patients with suicide ideation & $9.5 \pm 4.8$ \\
\hline Wigg et al, ${ }^{21} 2014$ & Cross-sectional & Brasil & 86 patients without suicide ideation & $6.2 \pm 4.1$ \\
\hline Wood et al, ${ }^{22} 2008$ & Cross-sectional & Canada & $\begin{array}{l}52 \text { mothers of children with } \\
\text { intractable epilepsy }\end{array}$ & $7.6 \pm 3.9$ \\
\hline Turaga et al, ${ }^{16} 2016$ & Observational study & India & 199 patients & $3.78 \pm 3.19$ \\
\hline Yazdi et al, ${ }^{23} 2013$ & Cross-sectional & Iran & 152 patients & 6.2 \\
\hline Manni et al, ${ }^{24} 2013$ & ND & Italy & 57 patients & $5.2 \pm 3.6$ \\
\hline Our work & Prospective cohort & Poland & 302 patients & $9.00 \pm 2.00$ \\
\hline Klobučníková et al, ${ }^{25} 2014$ & ND & Slovakia & I7 patients with nocturnal epilepsy & $|8.52 \pm 7.5|$ \\
\hline Klobučníková et al, ${ }^{25} 2014$ & ND & Slovakia & $\begin{array}{l}83 \text { patients with epileptic seizures } \\
\text { not related to sleep }\end{array}$ & $6.21 \pm 3.62$ \\
\hline Krishnan et al, ${ }^{26} 2012$ & Cross-sectional & South India & 50 with JME, on VPA only & $5.16 \pm 2.98$ \\
\hline Alvarez Guerrico et al, ${ }^{19} 2013$ & ND & Spain & 92 patients with drug resistant epilepsy & $6.79 \pm 3.81$ \\
\hline Chen et al, ${ }^{27} 201 \mathrm{l}$ & Cross-sectional & Taiwan & II7 patients & $6.5 \pm 3.8$ \\
\hline
\end{tabular}

Abbreviations: JME, juvenile myoclonic epilepsy; ND, no data; PSQI, Pittsburgh Sleep Quality Questionnaire; VPA, valproic acid.

When considering epilepsy-related factors that may affect sleep, some studies mention frequency and type of seizures or the use of antiepileptic drugs. ${ }^{28-32}$ For example, temporal lobe epilepsy is associated with a high rate of sleep disturbances, ${ }^{31}$ whereas nocturnal frontal lobe epilepsy is associated with the problems of sleep fragmentation and increased daytime sleepiness..$^{33}$ Another study showed that patients with partial seizures have a higher incidence of sleep complaints than those with generalized seizures. ${ }^{18}$ The results from the research by Chen et $a^{27}$ showed that a significantly higher prevalence of poor sleep quality was found in the partial seizure.

A correlation between seizure frequency and sleep was reported both in adults ${ }^{18}$ and in children population. ${ }^{34}$ However, other studies did not prove a relationship between sleep and frequency of seizure in adults with refractory partial epilepsy ${ }^{35}$ and with nocturnal frontal lobe epilepsy. ${ }^{36}$

Considering the impact of AEDs on sleep, as shown in the literature, the old generation antiepileptic drugs are more detrimental to sleep than the new generation drugs. ${ }^{37-39}$ The number and kind of antiepileptic drugs can affect sleep. Daytime sleepiness in patients with epilepsy significantly improves after reducing the number of antiepileptic drugs..$^{40,41}$

While gabapentin improves sleep quality, ${ }^{37}$ carbamazepine increases the NREM sleep and simultaneously reduces stage 1 and 2 of sleep. ${ }^{42}$ Data concerning the influence of phenytoin on sleep seem to be controversial. In the initial period of use, phenytoin reduces sleep latency and slightly increases the NREM sleep. However, when used for a long time, it only reduced sleep latency and had no influence on REM sleep. ${ }^{37,43}$ Ethosuximide has been shown to deteriorate the quality of sleep ${ }^{44}$ whereas valproates might cause sleep disorders by increasing stage 1 of sleep. ${ }^{37}$ Phenobarbital and benzodiazepines have been shown to alter normal sleep architecture..$^{45}$ It is probable that topiramate, lamotrigine, and levetiracetam have no effect on sleepiness. ${ }^{46}$

However, other studies have not confirmed the relationship between quality of sleep and epilepsy $y^{47,48}$ or antiepileptic medication and sleep. ${ }^{10}$ Many factors that are not related to the illness influence the length and quality of sleep. The so-called environmental factors are sleep-affecting factors which are independent of patients to some extent. They include noise level, light, surrounding temperature, humidity and ventilation rate, and type of bed.

Another important issue is sleep hygiene. In this case, certain behaviors and practices are dependent of a patient. They include time of going to sleep, consumption of food and drinks before sleep, watching TV, working on the computer, using the phone, reading, or physical activity before sleep. Sleeping in a room where everyday activities are not performed or sharing bed with another person is of key importance. The authors' own study showed that the majority of patients with epilepsy have their own bedroom (63.6\%) located in a quiet place $(57.6 \%)$ where there is appropriate temperature $(84.1 \%)$, have a comfortable bed and bed sheets (53\%), and that they do not go to sleep when TV or a computer is on, or while reading a book (55.6\%). The impact of other factors mentioned above on sleep was not assessed in the study.

Another important factor which might cause sleep disorders is night or shift work. In our study, this factor constituted 
an exclusion criterion for the participation in the study. Foldvary-Schaefer ${ }^{29}$ study showed that poor sleep hygiene can exacerbate seizures and excessive daytime sleepiness in patients with epilepsy.

\section{Conclusion}

Results of the study showed that more than a half of the patients with epilepsy were diagnosed with sleep-related diseases before taking the PSQI test. Insomnia was a disease which was prevalent in the majority of patients. Although the general result of PSQI test demonstrated bad sleep quality in the majority of patients, no relationship between certain clinical or sociodemographic variables and the final PSQI test result was proved. The study has some limitations, though. First, study participants were not comparable in terms of gender and AEDs used, which might have an influence on the final PSQI test result, as shown in the scientific literature. Second, study participants included patients who were on benzodiazepines, which might distort the study results due to the drugs' hypnotic effect. Further studies needed to be conducted to clarify the issue.

\section{Limitation}

One of the limitations of this study is that there was no control group (standard population) with which to compare the prevalence of sleep disorders among patients with epilepsy. However, to the best of our knowledge, this is the first published study about sleep disorders among polish patients with epilepsy. Hence, it should constitute a foundation for further detailed research.

\section{Disclosure}

The authors report no conflicts of interest in this work.

\section{References}

1. Sigurdson K, Asas NT. The public health and safety consequences of sleep disorders. Can J Physiol Pharmacol. 2007;85(1):179-183.

2. Europeans health affected by disturbed sleep Copenhagen, Bonn, 20 June 2016. Available from: http://www.who.int/healthinfo/global_ burden_disease/global_health_risks/en/index.html. Accessed January 5, 2017.

3. Mayer DG. Psychologia. Poznań, Poland: Zysk i S-ka; 2003.

4. Bazil CW. Epilepsy and sleep disturbance. Epilepsy Behav. 2003;4: S39-S45.

5. Niedermeyer E. Epileptic seizure disorders. In: Bazil CW, Malow BA, Sammaritano MR. Sleep and Epilepsy: The Clinical Spectrum. Amsterdam, Netherlands: Elsevier Science; 2002:149.

6. Sammaritano M, Levtova V, Samson-Dolfus D. Modifications of sleep architecture in patients with temporal lobe epilepsy. Epilepsia. 1994; $8: 124$.

7. Touchon J, Baldy-Moulinier M, Biliard M, Besset A, Cadhillac J. Sleep organization and epilepsy. Epilepsy Res. 1991;2:73-81.
8. Bazil CW, Malow BA, Sammaritano MR. Sleep and Epilepsy: The Clinical Spectrum. Amsterdam, Netherlands: Elsevier Science; 2002:20.

9. Kollár B, Buranová D, Varsik P. Epilepsia - súčasné možnosti liečby [Epilepsy - current treatment options]. Interná Med. 2002;9:579-583. Slovak [with English abstract].

10. Klobučníková K, Kollár K, Martinisková Z. Daytime sleepiness and changes of sleep architecture in patients with epilepsy. Neuro Endocrinol Lett. 2009;30(5):599-603.

11. Benavente FL, Javier SP. Pure sleep seizures: risk of seizures while awake. Epileptic Disord. 2007;9:1.

12. Buysse DJ, Reynolds CF 3rd, Monk TH, Berman SR, Kupfer DJ. The Pittsburgh Sleep Quality Index (PSQI): a new instrument for psychiatric research and practice. Psychiatry Res. 1989;28(2):193-213.

13. Piperidou C, Karlovasitou A, Triantafyllou N, et al. Influence of sleep disturbance on quality of life of patients with epilepsy. Seizure. 2008; 17(7):588-594.

14. Moser D, Pablik E, Aull-Watschinger S, Pataraia E, Wöber CH, Seidel S. Depressive symptoms predict the quality of sleep in patients with partial epilepsy - a combined retrospective and prospective study. Epilepsy Behav. 2015;47:104-110.

15. Khatami R, Zutter D, Siegel A, Mathis J, Donati F, Bassetti CL. Sleepwake habits and disorders in a series of 100 adult epilepsy patients - a prospective study. Seizure. 2006;15(5):299-306.

16. Turaga S, Soanpet P, Manikinda J, Kohat AK, Davidi SR. Observational study of prevalence of sleep disorder in patients with epilepsy. Int $J$ Epilepsy. 2016;3:20-23.

17. Skalski M. Zaburzenia Snu w Codziennej Praktyce. Warszawa, Poland: Medical Tribiune; 2012.

18. Bialasiewicz P, Nowak D. Obstructive sleep apnea syndrome and nocturnal epilepsy with tonic seizures. Epileptic Disord. 2009;11(4): 320-323.

19. Alvarez Guerrico I, Garcia Parra B, Lluis P, Royo I, Isabel FM, Rocamora R. Sleep quality in drug resistant epilepsy patients. Sleep Med. 2013;14S:e165-e238.

20. Carrion MJ, Nunes ML, Martinez JV, Portuguez MW, da Costa JC. Evaluation of sleep quality in patients with refractory seizures who undergo epilepsy surgery. Epilepsy Behav. 2010;17(1):120-123.

21. Wigg CM, Filgueiras A, Gomes Mda M. The relationship between sleep quality, depression, and anxiety in patients with epilepsy and suicidal ideation. Arq Neuropsiquiatr. 2014;72(5):344-348.

22. Wood LJ, Sherman EM, Hamiwka LD, Blackman MA, Wirrell EC. Maternal depression: the cost of caring for a child with intractable epilepsy. Pediatr Neurol. 2008;39(6):418-422.

23. Yazdi Z, Sadeghniiat-Haghighi K, Naimian S, Zohal MA, Ghaniri M. Prevalence of sleep disorders and their effects on sleep quality in epileptic patients. Basic Clin Neurosci. 2013;4(1):36-41.

24. Manni R, Cremascoli R, Sguazzin C, Terzaghi M. Subjective sleep quality in epilepsy patients with sleep-related seizures. Sleep Med. 2013;14S: e165-e238.

25. Klobučníková K, Čarnická Z, Wagnerová H, Šiarnik P. Is nocturnal epilepsy cause of disturbed quality of sleep and elevated daytime sleepiness? Neuro Endocrinol Lett. 2014;35(5):405-410.

26. Krishnan P, Sinha S, Taly AB, Ramachandraiah CT, Rao S, Satishchandra P. Sleep disturbances in juvenile myoclonic epilepsy: a sleep questionnaire-based study. Epilepsy Behav. 2012;23(3):305-309.

27. Chen NC, Tsai MH, Chang CC, et al. Sleep quality and daytime sleepiness in patients with epilepsy. Acta Neurol Taiwan. 2011;20(4):249-456.

28. de Weerd A, de Haas S, Otte A, et al. Subjective sleep disturbance in patients with partial epilepsy: a questionnaire based study on prevalence and impact on quality of life. Epilepsia. 2004;45(11):1397-1404.

29. Foldvary-Schaefer N. Sleep complaints and epilepsy: the role of seizures, antiepileptic drugs and sleep disorders. J Clin Neurophysiol. 2002; 19(6):514-521.

30. Foldvary N. Sleep and Epilepsy. Curr Treat Options Neurol. 2002;4(2): 129-135. 
31. Crespel A, Baldy-Moulinier M, Coubes P. The relationship between sleep and epilepsy in frontal and temporal lobe epilepsies: practical and physiopathologic considerations. Epilepsia. 1998;39(2):150-157.

32. Drake ME Jr, Pakalnis A, Bogner JE, Andrews JM. Outpatient sleep recording during antiepileptic drug monotherapy. Clin Electroencephalogr. 1990;21:170-173.

33. Zucconi M, Oldani A, Smirne S, Ferini-Strambi L. The macrostructure and microstructure of sleep in patients with autosomal dominant nocturnal frontal lobe epilepsy. J Clin Neurophysiol. 2000;17(1):77-86.

34. Batista B, Nunes ML. Evaluation of sleep habits in children with epilepsy. Epilepsy Behav. 2007;11(1):60-64.

35. Xu X, Brandenburg NA, McDermott AM, Bazi CL. Sleep disturbances reported by refractory partial-onset epilepsy patients receiving polytherapy. Epilepsia. 2006;47(7):1176-1183.

36. Vignatelli L, Bisulli F, Naldi I, et al. Excessive daytime sleepiness and subjective sleep quality in patients with nocturnal frontal lobe epilepsy: a case-control study. Epilepsia. 2006;47 (Suppl 5):73-77.

37. Legros B, Bazil C. Effects of antiepileptic drugs on sleep architecture: a pilot study. Sleep Med. 2003;4(1):51-55.

38. Gigli GL, Placidi F, Diomedi M, Maschio M. Nocturnal sleep and daytime somnolence in untreated patients with temporal lobe epilepsy: changes after treatment with controlled-release carbamazepine. Epilepsia. 1997;38(6):696-701.

39. Foldvary N, Perry M, Lee J, Dinner D, Morris HH. The effects of lamotrigine on sleep in patients with epilepsy. Eplepsia. 2001;42(12): 1569-1573.
40. Ramsay RE, Wilder BJ, Berger JR, Bruni J. A double-blind study comparing carbamazepine with phenytoin as initial seizure therapy in adults. Neurology. 1983;33(7):904-910.

41. Theodore WH, Porter RJ. Removal of sedative-hypnotic antiepileptic drugs from the regimens of patients with intractable epilepsy. Ann Neurol. 1983;13(3):320-324.

42. Montero F, Riemann D, Berger M. Antidepressant and antimanic drugs. In: Kales A. editor. The Pharmacology of Sleep. Berlin: Springer; 1995:465-490.

43. Rzewuska M. Leczenie bezsenności [Treatment of insomnia]. Farmakoterapia w psychiatrii i neurologii. 1998;1:56-92. Polish.

44. Rder UU, WolI' P. Effects of treatment with dipropylacetate and ethosuimide on sleep organ-isation in epileptic patients. In: Dam M, Gram L, Peury JK, editors. Advances in Epileptology. New York, NY: Raven; 1981:145-150.

45. Declerck AC, Wauquier A. Influence of antiepileptic drugs on sleep patterns. Epilepsy Res Suppl. 1991;2:153-163.

46. Bell C, Vanderlinden H, Hiersemenzel R, Otoul C, Nutt D, Wilson S. The effects of levetiracetam on objective and subjective sleep parameters in healthy volunteers and patients with partial epilepsy. J Sleep Res. 2002;11(3):255-263.

47. Ryvlin P, Rheims S, Risse G. Nocturnal frontal lobe epilepsy. Epilepsia. 2006;47 (Suppl 2):83-86.

48. Placidi F, Scalise A, Marciani MG, Romigi A, Diomedi M, Gigli GL. Effect of antiepileptic drugs on sleep. Clin Neurophysiol. 2000; 111 (Suppl 2):S115-S119.
Neuropsychiatric Disease and Treatment

\section{Publish your work in this journal}

Neuropsychiatric Disease and Treatment is an international, peerreviewed journal of clinical therapeutics and pharmacology focusing on concise rapid reporting of clinical or pre-clinical studies on a range of neuropsychiatric and neurological disorders. This journal is indexed on PubMed Central, the 'PsycINFO' database and CAS,

\section{Dovepress}

and is the official journal of The International Neuropsychiatric Association (INA). The manuscript management system is completely online and includes a very quick and fair peer-review system, which is all easy to use. Visit http://www.dovepress.com/testimonials.php to read real quotes from published authors. 